\title{
Clinical Outcomes of Arthroscopic Subscapularis Release for Obstetric Brachial Plexus Palsy with Internal Rotation Shoulder Contracture
}

Faisal Hassan Zayed ${ }^{1}$ MD

\author{
*Corresponding Author: \\ Faisal Hassan Zayed \\ faisalzayed@yahoo.com
}

Received for publication July 27, 2020; Accepted September 13, 2020; Published online September $18,2020$.

Copyright 2020 The Authors published by Al-Azhar University, Faculty of Medicine, Cairo, Egypt. All rights reserved. This an openaccess article distributed under the legal terms, where it is permissible to download and share the work provided it is properly cited. The work cannot be changed in anyway or used commercially.

doi:10.21608/aimj.2020.35348.1277

${ }^{l}$ Orthopedic Surgery Department, Faculty of Medicine, Al-Azhar University.

Disclosure: The author has no financial interest to declare in relation to the content of this article. The Article Processing Charge was paid for by the author.

\section{INTRODUCTION}

Difficult delivery can lead to a major neurological insult in the upper limb and it is called Obstetric brachial plexus palsy (OBPP). Most children (80$90 \%$ ) recover within few months after birth with minor or no residual functional deficits but unfortunately, some of them didn't recover completely and develop secondary deformity because of muscular imbalance with weak abductors and external rotators. ${ }^{1}$ The foremost affected roots are C5 - C6 and this can result in adduction and internal rotation contracture in most of cases. ${ }^{2-4}$

A lot of surgical techniques were reported to increase shoulder range of abduction and external rotation. These surgical procedures differ according to the patient's age and the degree of deformity. Contracture release, specific tendon transfers, and rotational osteotomies are examples of these techniques. Shortened structures should be released firstly to gain a good range of shoulder external rotation. 5,6

There's no consensus about the technique that gives the satisfactory results for shoulder function and mobility. Surgical procedures for OBPP are widely different with no clear evidence to favor one procedure over the other in addition to insufficient 


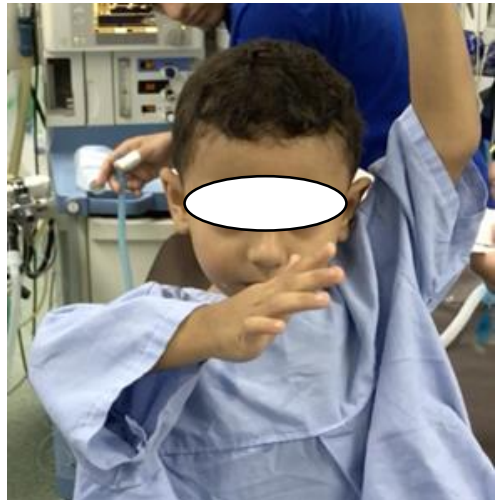

Fig. 1: Preoperative active range of motion.

Inclusion criteria: This study included patients with shoulder internal rotation contractures, limitation in passive external rotation (less than 10 degrees), younger than 6 years before uncorrectable glenoid deformities, with no history previous shoulder surgery.

\section{Surgical technique:}

All patients were operated under general anaesthesia and we used the lateral decubitus position for all patients because we found a great difficulty to use the beach chair position in such small children. The upper extremity was draped in a classic pattern and positioned freely to re-evaluate the passive range of motion under anaesthesia before and after release. The assistant was holding the upper extremity in a position of $20^{\circ}$ abduction and neutral rotation with gentle traction during the procedure with no need for a traction system. We used a small scope $(2.7 \mathrm{~mm} /$ $30^{\circ}$ angle), $90^{\circ}$ radiofrequency probe, and $2.5 \mathrm{~mm}$ shaver blades for this procedure. The posterior portal was made at the posterior soft spot about $1 \mathrm{~cm}$ below and medial to the posterolateral angle of the acromion. Shoulder abduction and lateral traction of the arm were helpful to enter the contracted joint with a wide bore needle (18G epidural needle) and inflating the joint with a few amount of saline to distend this small joint, then insert a blunt trocar through the posterior portal. Then we made the anterior portal using outside-in technique under direct visualization at the rotator interval just above the subscapularis tendon. We didn't use a $5.5-\mathrm{mm}$ working cannula as in adult shoulder but we used 18G epidural needle as an out-flow cannula and introduced the radiofrequency electrode directly through the anterior portal to start the release of subscapularis tendon and anterior capsule until we see the muscle fibres (figure 2: a \& b). In most of the cases (22 out of 28 ), this release was sufficient to gain more than $45^{\circ}$ of intraoperative passive external rotation (figure 3 : a \& b). In few cases (6 out of 28), we would have to extend our release to include rotator interval, coracohumeral ligament, superior and inferior glenohumeral ligaments to attain over $45^{\circ}$ of intraoperative passive external rotation.

After closure of skin incisions, shoulder spica cast was applied for all patients with maximum external rotation and $90^{\circ}$ abduction. The cast was then removed after 4 weeks and physical therapy was started including gentle stretching and night bracing for another 4 weeks. All patients underwent regular postoperative follow-up at 4 weeks, 8 weeks, 3 months, 6 months, 1 year, and at the end of follow up 2 years postoperatively reporting the ranges of motion, shoulder function, and shoulder strength using the Mallet scoring system.
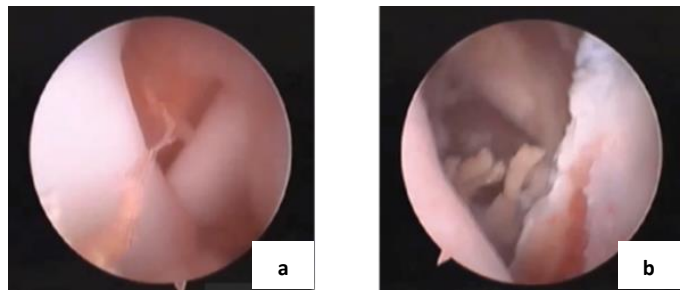

Fig. 2: Subscapularis tendon before (a) and after (b) release.
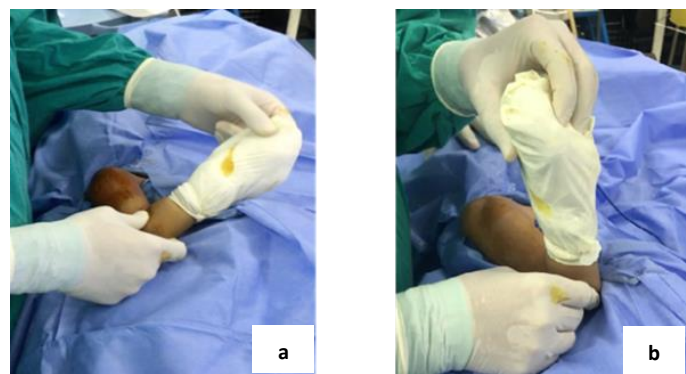

Fig. 3: Intraoperative passive external rotation before (a) and after release (b).

\section{Statistical analysis:}

Statistical analysis was carried out using the IBM SPSS Statistics 26 for Windows. Results were expressed as mean \pm SD for quantitative variables. Confidence interval of $95 \%$ and $p<0.05$ were considered statistically significant.

\section{RESULTS}

This prospective study was conducted over seven years (between 2012 and 2018), and included 28 patients who were presented with shoulder internal rotation contracture secondary to obstetric palsy before the age of 6 years with passive external rotation $<10^{\circ}$. They were treated with shoulder arthroscopy to release the subscapularis tendon without any tendon transfer. The average age was 3 years ( $2-5$ years). Twenty-two children had an injury at $\mathrm{C} 5-\mathrm{C} 6$, four had an injury at $\mathrm{C} 5-\mathrm{C} 6-\mathrm{C} 7$ and two had a complete injury. The average follow-up was 27 months ( 24 - 36 months). Tables 2 and 3 summarize the demographic and clinical data of all patients. The mean passive ER was $70^{\circ}\left(40^{\circ}-90^{\circ}\right)$ and the mean active ER was $60^{\circ}\left(20^{\circ}-90^{\circ}\right)$ at the end of follow up (figure 4: a, b, c \& d). The mean global Mallet score improved from 11.29 $\pm 1.06 \mathrm{SD}$ (range from 10 to 13 ) preoperatively to $17.38 \pm 2.14$ SD (from 13 to 20) postoperatively. No significant difference was found in Mallet score between patients with partial plexus injury at the level of C5C6 and patients with partial plexus injury at the level of C5-C6-C7 roots, while there was a significant difference between patients with partial and complete plexus injury with low Mallet score for patients with complete plexus injury. There have been no intraoperative or postoperative complications. 


\begin{tabular}{|c|c|c|c|c|c|}
\hline Functional parameter & Grade I & Grade II & Grade III & Grade IV & Grade V \\
\hline Global abduction & None & $\leq 30^{\circ}$ & $30-90^{\circ}$ & $>90^{\circ}$ & Normal \\
\hline External rotation & None & $<0^{\circ}$ & $00^{\circ}-20^{\circ}$ & $>20^{\circ}$ & Normal \\
\hline Hand to back of neck & None & Impossible & Difficult & Easy & Normal \\
\hline Hand to mouth & None & $\begin{array}{c}\text { Marked Trumpet } \\
\text { sign }\end{array}$ & $\begin{array}{c}\text { Partial Trumpet } \\
\text { sign }\end{array}$ & $\begin{array}{c}\text { Easy with }<40^{\circ} \\
\text { abduction }\end{array}$ & Normal \\
\hline Internal rotation & None & Not possible & To S1 & To T12 & Normal \\
\hline
\end{tabular}

Table 1: Mallet score for shoulder function. ${ }^{8}$

\begin{tabular}{|c|c|c|c|c|} 
Age & Sex & Side & Roots affected & Follow up \\
\hline 3 years (2-5) & 16 boys and 12 & Rt. 16, Lt. 12 & 22 pt. C5,6 & 27 months (24-36) \\
years & girls & & 4 pt. C5,6,7 & \\
& & & 2 pt. Complete & \\
\hline
\end{tabular}

Table 2: Demographic data of all patients.

\begin{tabular}{|c|c|c|c|}
\hline & Preoperative & Postoperative & P-value \\
\hline Passive ER & $5.45^{\circ}$ (from $-15^{\circ}$ to $\left.10^{\circ}\right)$ & $70^{\circ}\left(\right.$ from $40^{\circ}$ to $\left.90^{\circ}\right)$ & $0.024<0.05$ \\
\hline Active ER & Unmeasurable in most cases & $60^{\circ}$ (from $20^{\circ}$ to $\left.90^{\circ}\right)$ & \\
\hline Mallet score & $11.29 \pm 1.06 \mathrm{SD}$ (from 10 to 13$)$ & $17.38 \pm 2.14 \mathrm{SD}$ (from 13 to 20$)$ & $0.013<0.05$ \\
\hline
\end{tabular}

Table 3: Clinical data of all patients.

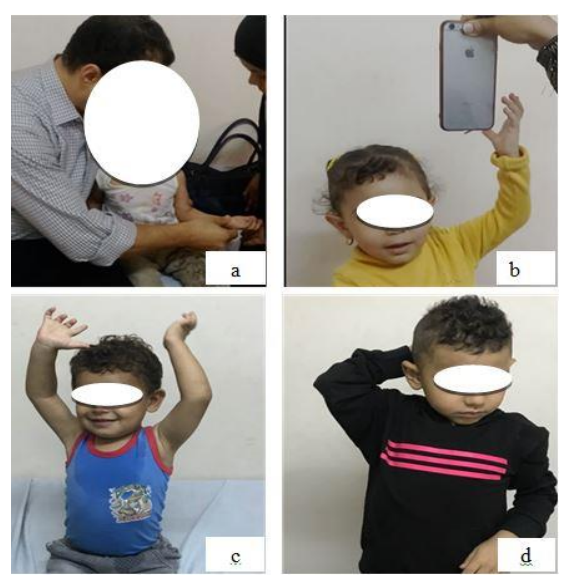

Fig. 4: a, b, c \& d- postoperative ROM

\section{DISCUSSION}

The foremost common secondary shoulder deformity in OBPP is that the defective abduction and external rotation because of internal rotation contracture. ${ }^{9}$ There are several surgical procedures reported to enhance shoulder abduction and external rotation. ${ }^{10-12}$ Younger age groups may benefit from procedures dealing with soft tissues before the appearance of fixed bone deformities. ${ }^{13,14}$ Arthroscopic subscapularis release has potential advantages including less invasiveness, evaluation of any associated intraarticular pathology, decreased blood loss, and low incidence of infection. ${ }^{5}$

This study shows promising results in the form of improved Mallet score and increased range of 
shoulder motion specially abduction and external rotation after arthroscopic subscapularis release.

Many authors reported improvement of shoulder internal rotation contracture after arthroscopic subscapularis release. ${ }^{15-17}$ In their study on 33 children, Pearl et al reported that arthroscopic subscapularis release without tendon transfer can restore passive external rotation and a centered humeral head in children younger than three years old. ${ }^{18}$ Newman and colleagues treated 13 children (mean age 4.7 years) with isolated subscapularis release and reported results comparable with those obtained with tendon transfer. ${ }^{19}$ Kozin et al reported a great improvement in all outcomes after arthroscopic release with or without tendon transfer in 44 children with OBPP. ${ }^{20}$ Elzohairy and Salama study included 15 children with OBPP and treated them with an arthroscopic subscapularis release alone and they reported good restoration of shoulder range of motion and functions. ${ }^{21}$

Similar successful and promising results were achieved after arthroscopic release alone procedure within the current study which included 28 patients with average age 3 years ( $2-5$ years) and average follow-up 27 months (24 - 36 months)

The mean passive ER was $70^{\circ}\left(40^{\circ}-90^{\circ}\right)$ and the mean active ER was $60^{\circ}\left(20^{\circ}-90^{\circ}\right)$ at the end of follow up. The mean global Mallet score improved from 11.29 $\pm 1.06 \mathrm{SD}$ (range from 10 to 13) preoperatively to $17.38 \pm 2.14 \mathrm{SD}$ (range from 13 to 20) postoperatively.

In this study, subscapularis tendon release alone was sufficient to gain more than $45^{\circ}$ of intraoperative passive external rotation in most of cases (22 out of 28 ). In few cases (6 out of 28 ) we would have to extend our release to include rotator interval, coracohumeral ligament, superior and inferior glenohumeral ligaments to attain over $45^{\circ}$ of intraoperative passive external rotation.

We expect that complete brachial plexus injury could be a bad prognostic factor because in our study we have two cases with low postoperative score (13 points) and both of them were presented with complete brachial plexus injury. There have been no intraoperative or postoperative complications. We used the Mallet scoring system because it remains the foremost commonly used system in several OBPP centres. ${ }^{4,22,23}$

The strength of this study is that arthroscopic release procedure allows more precise release with minimally invasive technique. Also, dynamic assessment may be performed under arthroscopic control. Another strength point is that this study gives information about not commonly used procedure managing not so rare cases. There were some limitations of this study including; no control group, the long learning curve of the procedure due to infrequent pediatric shoulder arthroscopy cases, with high risk for axillary nerve injury due to its proximity to the subscapularis.
Lastly, we recommend arthroscopic subscapularis release in specific patients with internal rotation shoulder contracture in the early stages of development for better life quality, better mobility, and performance.

\section{CONCLUSION}

Arthroscopic subscapularis release alone without tendon transfer for internal rotation shoulder contracture in OBPP is a minimally invasive procedure and shows promising results in the younger age groups.

\section{REFERENCES}

1. Pondaag W, Malessy MJA, Van Dijk JG, Thomeer RTW. Natural history of obstetric brachial plexus palsy: a systematic review. Dev Med Child Neurol. 2007; 46:138-144.

2. Jackson ST, Hoffer MM, Parrish N. Brachialplexus palsy in the newborn. J Bone Joint Surg. 1988; 70-A:1217-20.

3. Hale HB, Bae DS, Waters PM. Current concepts in the management of brachial plexus birth palsy. J Hand Surg Am. 2010; 35: 322-31.

4. Gilbert A. Long-term evaluation of brachial plexus surgery in obstetrical palsy. Hand Clin. $1995 ; 11: 583-94$.

5. Mehmet A, Burak A, Kerem B, et al. Arthroscopic release of the subscapularis for shoulder contracture of obstetric palsy. Eur $J$ Orthop Surg Traumatol. 2012; 22:25-28.

6. Tuna P, Ali E, Serkan B, et al. Arthroscopic versus open release of internal rotation contracture in the obstetrical brachial plexus paralysis (OBPP) sequela. $J$ of shoulder and elbow surgery. Volume 28, Issue 1, January 2019, 28-35.

7. Elias N, Elie S, Elias M, et al. Proximal subscapularis release for the treatment of adduction-internal rotation shoulder contracture in obstetric brachial plexus palsy Child Orthop. 2015; 9:339-344.

8. Mallet J. Obstetrical paralysis of the brachial plexus. II. Therapeutics. Treatment of sequelae. Must transplants be performed? Rev Chir Orthop Reparatrice Appar Mot. 1972; 58(suppl 1):201-204.

9. Al-Qattan MM. Classification of secondary shoulder deformities in obstetric brachial plexus palsy. Journal of Hand Surgery. 2003; 28 (5):483-86.

10. Kokkalis ZT, Ballas EG, Mavrogenis AF. Arthroscopic release of shoulder internal rotation contracture in children with brachial 
plexus birthpalsy. Acta Orthop Belg. 2013; 79 (4):355-60.

11. Carlioz H, Brahimi L. Place of internal disinsertion of the subscapularis muscle in the treatment of obstetric paralysis of the upper limb in children. Ann Chir Infant. 1971 MarApr; 12 (2):159-67.

12. Pearl ML. Arthroscopic release of shoulder contracture secondary to birth palsy: an early report on findings and surgical technique. Arthrosc J Arthrosc Relat Surg. 2003; 19:57782.

13. Birch R. Birth lesions of the brachial plexus. In: Birch R, Bonney G, Perrycb Wynn (eds) Surgical disorders of the peripheral nerves. Curchill Livingstone, London, 1998; pp 209233

14. Waters PM, Peljovich AE. Shoulder reconstruction in patients with chronic brachial plexus birth palsy. A case control study. Clin Orthop Relat Res. 1999; 364:144-152.

15. Kany J, Kumar HA, Amaravathi RS, et al. A subscapularis preserving arthroscopic release of capsule in the treatment of internal rotation contracture of shoulder in Erb's palsy (SPARC procedure) J Pediatr Orthop B. 2012; 21 (5):469-73.

16. Mehlman CT, DeVoe WB, Lippert WC, et al. Arthroscopically assisted Sever-L'Episcopo procedure improves clinical and radiographic outcomes in neonatal brachial plexus palsy patients. J Pediatr Orthop. 2011; 31:341-51.

17. Kozin SH, Chafetz RS, Barus D, et al. Magnetic resonance imaging and clinical findings before and after tendon transfers about the shoulder in children with residual brachial plexus birth palsy. J Shoulder Elbow Surg. 2006; 15:554-61.

18. Pearl ML, Edgerton BW, Kazimiroff PA, et al. Arthroscopic release and latissimus dorsi transfer for shoulder internal rotation contractures and glenohumeral deformity secondary to brachial plexus birth palsy. $J$ Bone Joint Surg. 2006; 88-A:564-74.

19. Newman CJ, Morrison L, Lynch B, et al. Outcome of subscapularis muscle release for shoulder contracture secondary to brachial plexus palsy at birth. J Pediatr Orthop. 2006; 26:647-51 .

20. Kozin SH, Boardman MJ, Chafetz RS, et al Arthroscopic treatment of internal rotation contracture and glenohumeral dysplasia in children with brachial plexus birth palsy. $J$ Shoulder Elbow Surg. 2010; 19:102-110.
21. Mohamed Mansour Elzohairy and Adel Mohamed Salama. Evaluation of functional outcomes and preliminary results in a case series of 15 children treated with arthroscopic release for internal rotation contracture of the shoulder joint after Erb's palsy. Journal of Children's Orthopaedics. 2016; 10(6): 665-72.

22. Cuesta FJG, Prats FL, Lopez FJG, et al. The role of bone operations as palliative surgical treatment for the sequelae of obstetrical brachial paralysis in the shoulder. Acta Orthopaedica Belgica. 1982; 48 (5):757-61.

23. Nualart L, Cassis N, Ochoa R. Functional improvement with the Sever L'Episcopo procedure. Journal of Pediatric Orthopaedics. 1995; 15 (5):637-40. 